\title{
Optimal Coordination of Reservoirs for Flood Control using a Stochastic Approach
}

\author{
Rafael Enrique Fragozo Díaz \\ GLF Colombia S.A.S., Cra 43 A \# 1 - 50, \\ Medellín 050010, Colombia,
}

\author{
Jesús María López Lezama \\ Departamento de Ingeniería Eléctrica, \\ Universidad de Antioquia Calle 70 No \\ 52-21, Medellín 050010, Colombia,
}

\author{
Nicolás Muñoz Galeano \\ Departamento de Ingeniería Eléctrica, \\ Universidad de Antioquia Calle 70 No \\ 52-21, Medellín 050010, Colombia,
}

ORCID: 0000-0002-2369-6173

\begin{abstract}
This paper presents a stochastic approach model for the optimal coordination of reservoirs. The proposed approach simulates the behavior of two reservoirs in parallel as primary infrastructure for flood control. The deterministic version consists on a set of equations that represent the inflows and outflows of the reservoirs, as well as the constraints associated with flood control. The stochastic version of the model resorts to a stochastic series generator, which produces different values of water flows which are processed through a deterministic model. With this information a set of possible operating scenarios is generated, and a reliability study is carried out, applied to the flood control zone. The validation of the proposed model is performed using the technical parameters of two reservoirs of the Colombian electrical system. With this type of models, new decision-oriented tools are offered related to flood prevention and control.
\end{abstract}

Keywords: Flood control, multipurpose reservoir, stochastic optimization, power systems.

\section{INTRODUCTION}

There are several international studies related to flood control and the optimal functioning of reservoirs. In China, for example, Hongwei and Zezhong presented the benefits of flood control along the Yellow River [1]. In [2], a reservoir operation scheme for flood control based on real-time information and forecasts is proposed for the Three Gorges project. In [3], a flood control model for the rainy seasons is proposed, applying a reliability and risk analysis based on hydrological forecasts also for the Three Gorges project. In Mozambique, a flood control model was proposed using a hydroelectric reservoir to mitigate the social impact of electricity generation [4]. Design elements for flood protection dikes in France are presented in [5]. In Vietnam, the operation of a reservoir based on several guide curves depending on the level of criticality was proposed for the Red River [6]. In Malaysia, the operation of reservoirs in cascade coordinated by means of guide curves was proposed, in which the volumes of the reservoirs are related by the curves [7]. In Canada, the flood control problem was addressed considering the impact of the basin downstream the plant due to discharges [8]. In [9], a state of the art of the models and optimization techniques used for the operation of hydroelectric reservoirs is presented. In [10], a stochastic model is proposed for flood control in Colombia during the $\mathrm{La}$ Niña phenomenon, using the infrastructure of a hydroelectric reservoir. In [11], a study of dynamic flood simulation applied to a Colombian case is presented. Other studies related to Colombian hydrology and reservoir control are presented in [12] and [13], respectively.

Colombia is a country highly affected by climatic phenomena such as El Niño and La Niña. The effects of these phenomena tend to have a high impact on the population, the economy and the infrastructure. The rainy season experienced, between 2010 and 2012, is considered by experts as the most devastating in the last 40 years and has been an important point to reflect on the country's response capacity to natural disasters to which it is exposed. In 2017, alerts were activated again for possible floods, taking into account that $30.4 \%$ of the generation reservoirs in the country had reached their maximum capacity, and recently the Institute of Hydrology and Environmental Studies (IDEAM) warns of the probability of a 75\% occurrence of a La Niña in the last months of 2020. This situation has generated concern in the inhabitants: mainly ranchers and farmers, located downstream the generation plants

In this paper a stochastic model is proposed to coordinate the operation of two reservoirs in parallel, in order to obtain an optimal balance between power generation and flood control, avoiding discharges and controlling the downstream flood zone, minimizing in this way the socio-environmental risks associated with floods.

\section{METHODOLOGY}

\subsection{Deterministic model}

The basic model of the energy system of a hydroelectric generator is composed of a reservoir and its corresponding flows. Figure 1 illustrates the schematic of the analyzed model, in which two reservoirs intervene. The variables used are: flows contributed by the basins upstream of the reservoirs (series E1 and series E2), discharge flows from the reservoirs for the purpose of producing electricity (VG1 and VG2), 
discharge flows by dumping (Vv1 and Vv2), a flow attributable to an external river, which is not controlled by the reservoirs under study (external river), an unbalanced flow of each reservoir (evaporation + seepage) and finally, a flood control zone ( FCZ), where a maximum flow is set in order to protect a population.

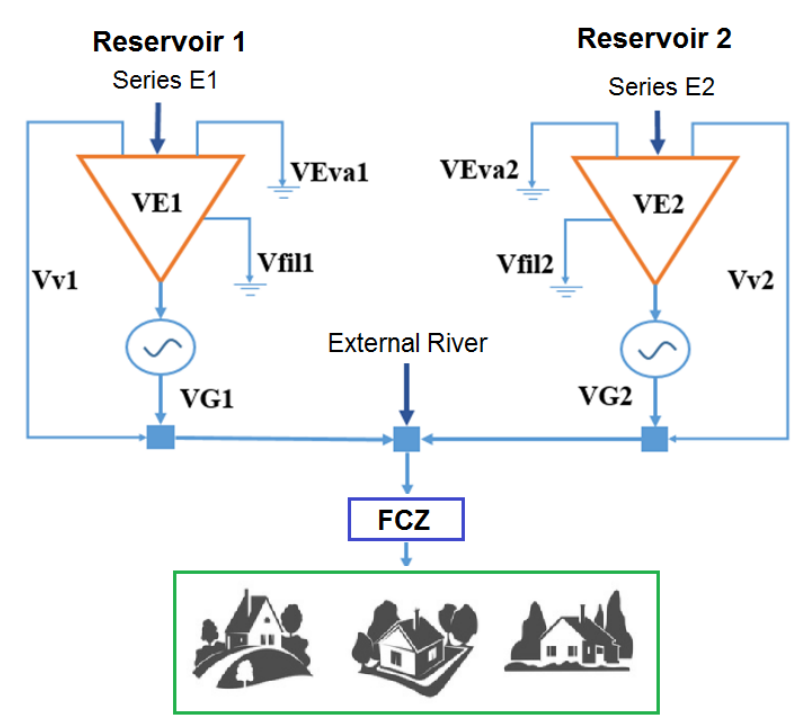

Figure 1. Schematic representation of the reservoirs under study

The objective function of the optimization problem is given by equation (1), which seeks to maximize profits from energy sales. The objective function is composed of the maximization of income from energy sales minus the penalties for discharges and flooding in the FCZ. The constraints given by equations (2) and (3) indicate the minimum and maximum limits of the discharge volume through the generation pipelines and the volume of each reservoir, respectively. The restriction given by (4) indicates the limit of the volume in the flood control zone in each time interval. Equation (5) represents the volume balance of each reservoir; equation (6) indicates the generation conversion factor and finally equation (7) represents the total volume in the FCZ.

$$
\begin{aligned}
& \operatorname{Max} \sum_{j=1}^{m}\left(\sum_{i=1}^{n} P_{j} * G_{i j}-V_{V_{i j}} * P e n_{v_{i j}}\right)-V_{\text {Inu }} \\
& \text { *Pen } \text { inu }_{j}
\end{aligned}
$$

Suject to:

$$
\begin{aligned}
& V_{G_{i_{\text {min }}}} \leq V_{G_{i}} \leq V_{G_{i_{\text {máx }}}} \\
& V_{E_{i_{\text {min }}}} \leq V_{E_{i j}} \leq V_{E_{i_{\text {máx }}}} \\
& V_{Z C_{j}}-V_{\text {Inu }_{j}} \leq V_{Z C_{\text {máx }}}
\end{aligned}
$$

$$
\begin{aligned}
& V_{E_{i}}=V_{E_{i j-1}}+V_{Q_{i}}-V_{G_{i}}-V_{E F_{i}}-V_{V_{i}} \\
& G_{i}=V_{G_{i}} * F C_{i} \\
& V_{F C Z_{j}}=\sum_{i=1}^{n}\left(V_{G_{i j}}+V_{V_{i j}}\right)+V_{Q_{\text {ext }}}
\end{aligned}
$$

Where:

$$
\begin{aligned}
& \mathrm{P}_{\mathrm{j}} \quad \text { : Average spot price for trading day } \mathrm{j} \\
& \mathrm{G}_{\mathrm{ij}} \quad \text { : Energy generated by reservoir } \mathrm{i} \text { in day } \mathrm{j} \\
& \mathrm{V}_{\mathrm{V}_{\mathrm{ij}}} \quad \text { : Discharge of reservoir } \mathrm{i} \text { in day } \mathrm{j} \\
& \text { Pen }_{v_{i j}} \quad \text { : Penalty for discharges, applied to } \\
& \text { reservoir } \mathrm{i} \text { in day } \mathrm{j} \\
& \mathrm{V}_{\text {Inu }_{\mathrm{j}}} \quad \text { : Volume of water above the maximum } \\
& \text { in the FZC in day } \mathrm{j} \\
& \text { Pen }_{\text {inu }_{j}} \quad \text { : Penalty for flooding in the control area, } \\
& \text { applied in day } j \\
& \mathrm{~V}_{\mathrm{G}_{\mathrm{i} \text { min }}} \quad \text { : Minimum discharge volume of } \\
& \text { reservoir i } \\
& \mathrm{V}_{\mathrm{G}_{\mathrm{i}}} \quad \text { : Discharge of reservoir i } \\
& \mathrm{V}_{\mathrm{G}_{\text {i máx }}} \quad \text { : Maximum discharge of reservoir } \mathrm{i} \\
& \mathrm{V}_{\mathrm{E}_{\mathrm{m} \text { min }}} \quad \text { : Minimum volume of reservoir i } \\
& \mathrm{V}_{\mathrm{E}_{\mathrm{ij}}} \quad \text { : Volume of reservoir } \mathrm{i} \\
& \mathrm{V}_{\mathrm{E}_{\text {máx }}} \quad \text { : Maximum volume of reservoir } \mathrm{i} \\
& \mathrm{V}_{\mathrm{FCZ}_{\mathrm{j}}} \quad \text { : Volume in the FCZ in day } \mathrm{j} \\
& \mathrm{V}_{\mathrm{ZC}_{\text {máx }}} \quad \text { : Maximum volume allowed in the } \mathrm{FCZ} \\
& \mathrm{V}_{\mathrm{E}_{\mathrm{ij}-1}} \quad \text { : Volume of reservoir } \mathrm{i} \text { in day } \mathrm{j}-1 . \\
& \mathrm{V}_{\mathrm{Q}_{\mathrm{i}}} \quad \text { : Volume of basins of the reservoir } i \text {. } \\
& \mathrm{V}_{\mathrm{EF}_{\mathrm{i}}} \quad \text { : Unbalanced volume composed of } \\
& \text { filtration plus evaporation from } \\
& \text { reservoir } \mathrm{i} \text {. }
\end{aligned}
$$

\subsection{Stochastic approach}

Studies related to hydrological prediction contain a high level of uncertainty when trying to recreate future hydrological scenarios. This is why stochastic models take relevance during the analysis of problems related to the administration of water 
resources and in the management and operation of reservoirs.

Stochastic models seek to include and reflect the uncertainty of the variables under study in the results of the models. In this case, a stochastic model is proposed, through which a large number of possible scenarios are generated, in order to establish probabilities of occurrence and be able to make decisions under desired confidence levels.
Figure 2 presents a schematic diagram of the proposed model. It is basically composed of a stochastic series generator, which produces different values of water flows which are processed through the deterministic optimization model presented in Section 2.1. The proposed model generates possible operation scenarios, to which a reliability study is carried out, applied to the FCZ.
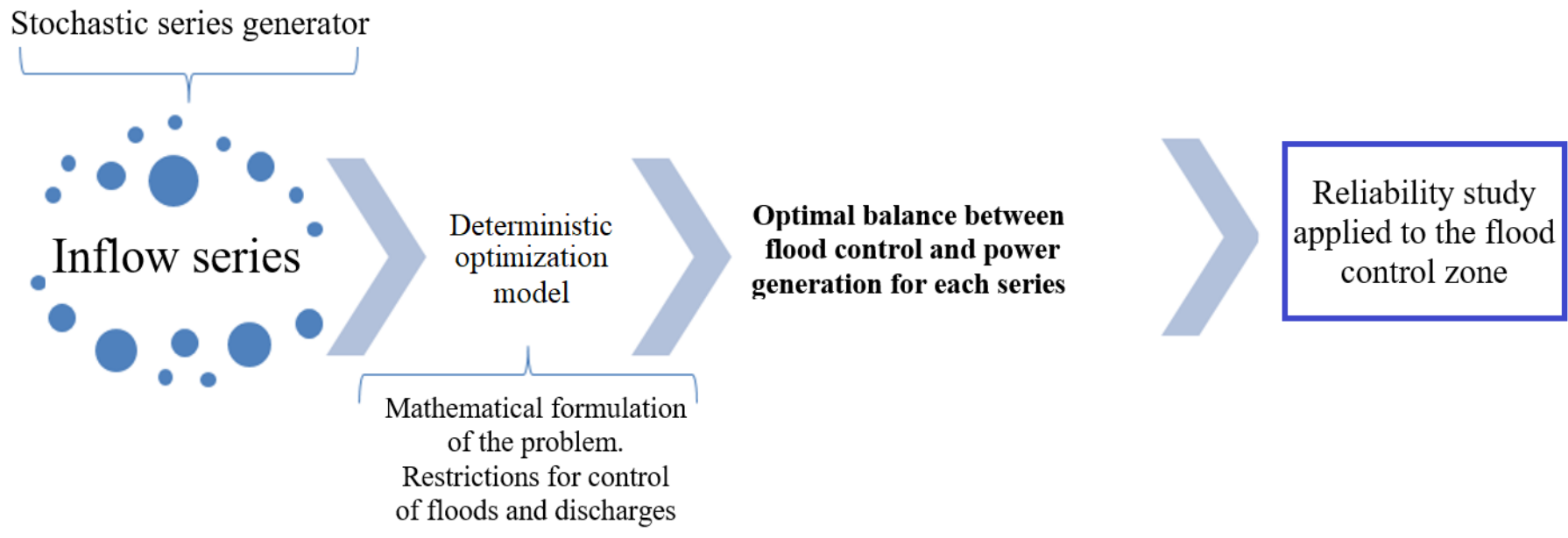

Figure 2. Structure of the stochastic model

The flow series generator illustrated in Figure 3 uses as input information the hydrological forecasted data, which is fixed as the mean of a normal distribution, which standard deviation is given by the standard deviation of the historical data of the river under study. After completing the iterative process for each of the hydrological series generated, there is a dispatch number equal to the number of series generated. For each of the selected dispatches, the impact generated in the FCZ is evaluated and the level of reliability is calculated based on the magnitude of the flood.

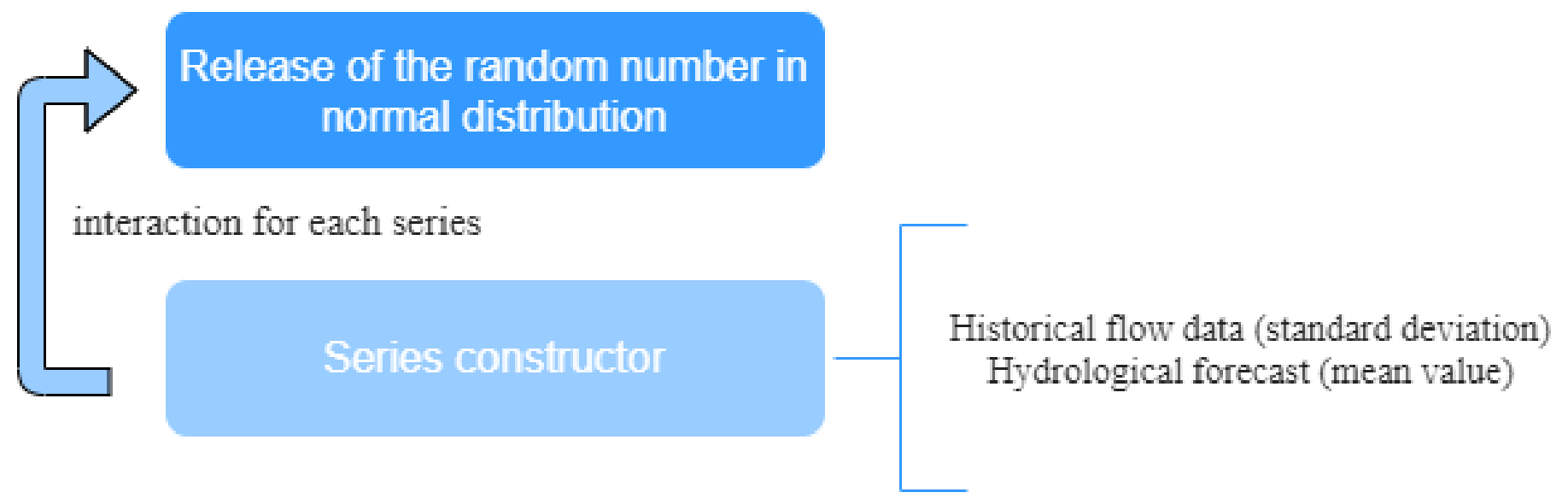

Flow series

Figure 3. Structure of the water flow series generator 
International Journal of Engineering Research and Technology. ISSN 0974-3154, Volume 13, Number 10 (2020), pp. 2839-2844

(C) International Research Publication House. https://dx.doi.org/10.37624/IJERT/13.10.2020.2839-2844

\section{TESTS AND RESULTS}

Table 1 presents the main technical parameters for the deterministic model. These parameters correspond to real values of two reservoirs that are part of the Colombian electrical system and can be consulted in [14]. The maximum volume in FCZ was set to $20 \mathrm{Mm} 3$, which is equivalent to $85 \%$ of the average water flow that would circulate through the small village downstream the reservoir, according to the historical hydrological series.

The water flow series generator was used to generate 30 series for each of the input flows of the system represented in Figure 1. With this result it is possible to recreate a series of possible operating scenarios according to the historical flows reported by the market agents in Colombia. Figures 4,5 and 6 show respectively the results obtained with the flow series generator for Reservoir 1, Reservoir 2 and the external river, based on the historical series years 1978 to 2015 . The graphs highlight, in red, the forecasted (mean) for each of the groups of series generated.
Table 1. Technical Parameters of the analyzed reservoirs

\begin{tabular}{lcc}
\hline \multicolumn{1}{c}{ Parameter } & Reservoir 1 & Reservoir 2 \\
\hline Minimum Volume (Mm3) & 17.71 & 23.30 \\
Maximum Volume (Mm3) & 782.05 & 610.89 \\
Convertion Factor (MW/Mm3/s) & $2,711.25$ & $1,945.89$ \\
$\begin{array}{l}\text { Maximum Discharge Volume } \\
\text { (Mm3-day) }\end{array}$ & 10.62 & 12.33 \\
$\begin{array}{l}\text { Maximum Discharge Capacity } \\
\text { (MWh-day) }\end{array}$ & $28,798.90$ & $24,000.61$ \\
$\begin{array}{l}\text { Maximum Spillage Capacity } \\
\text { (Mm3-day) }\end{array}$ & 362.88 & 864 \\
$\begin{array}{l}\text { Minimum Discharge Volume } \\
\text { (Mm3-day) }\end{array}$ & 0.53 & 0.12 \\
$\begin{array}{l}\text { Maximum Generation Capacity } \\
\text { (MWh-day) }\end{array}$ & $1,439.67$ & 239.34 \\
$\begin{array}{l}\text { Net Effective Generation } \\
\text { Capacity (MW) }\end{array}$ & 1,200 & $1,000$. \\
$\begin{array}{l}\text { Maximum Volume in the FCZ } \\
\text { (Mm3) }\end{array}$ & 20 & 20 \\
\hline
\end{tabular}

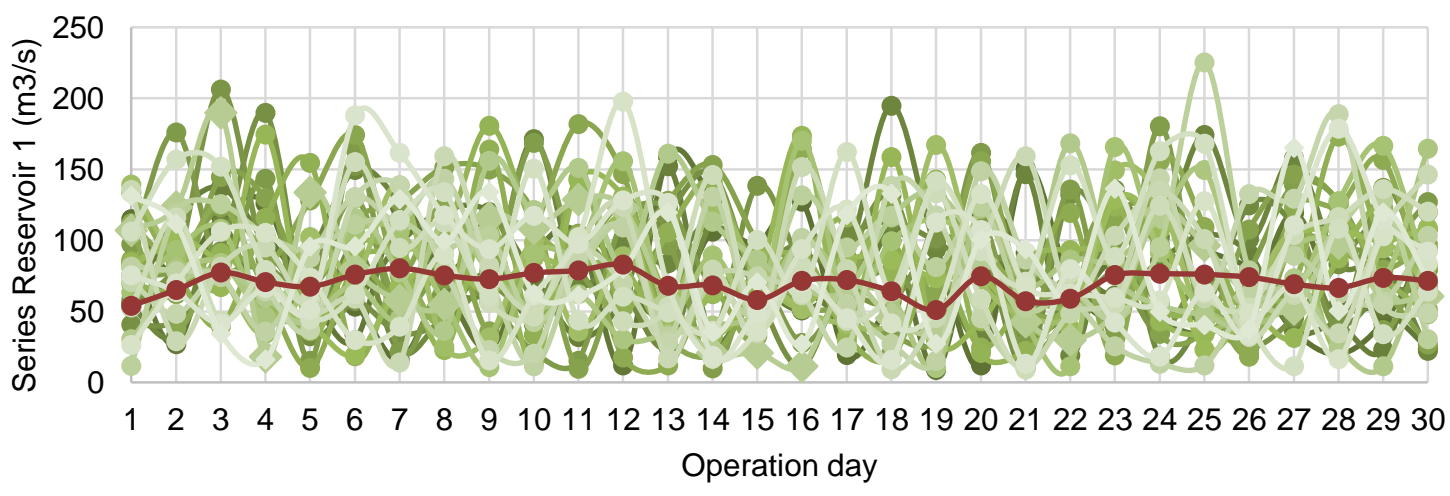

Figure 4. Flow series generated for Reservoir 1

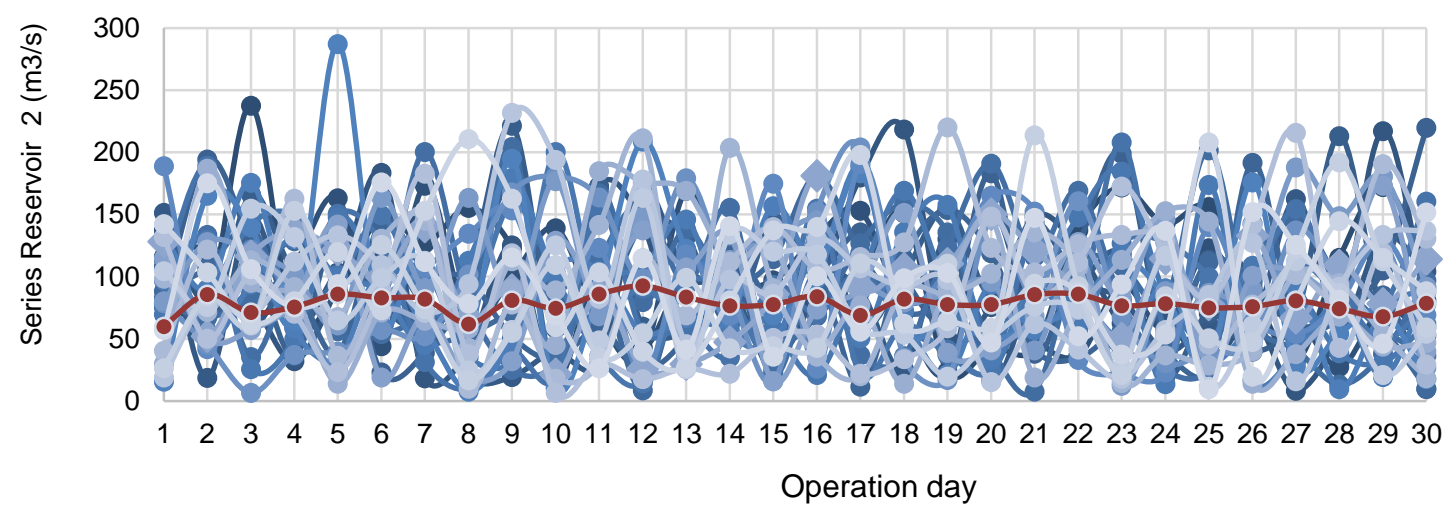

Figure 5. Flow series generated for Reservoir 2 


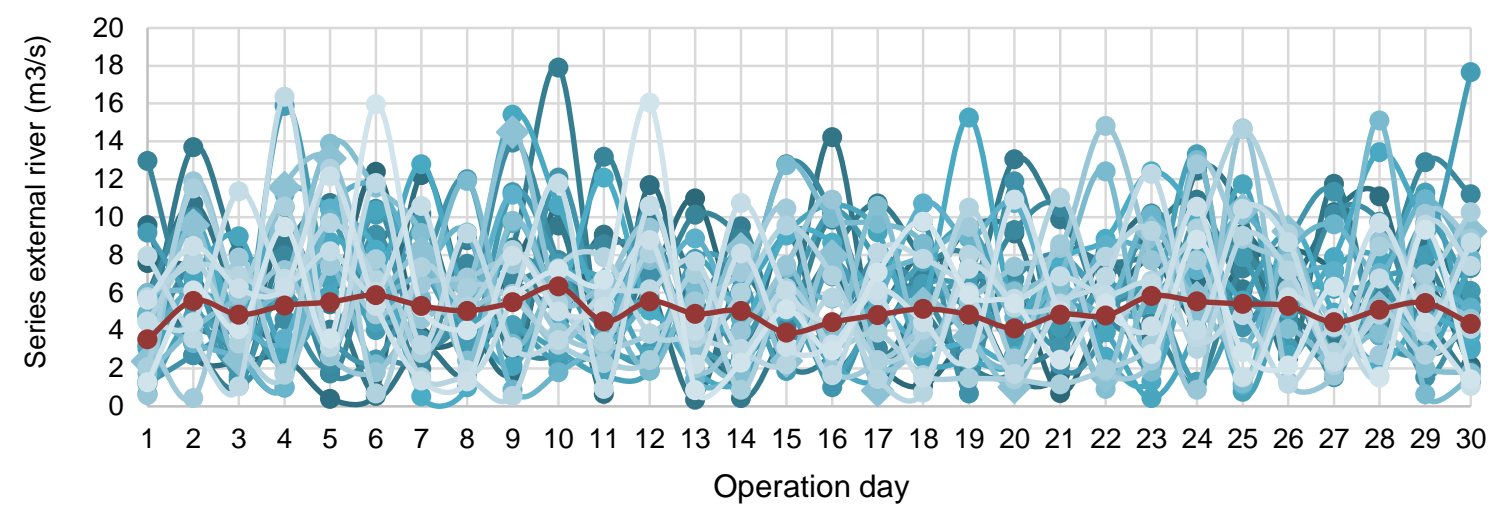

Figure 6. Flow series generated for the external river

Once the water flow series were generated, 5 of the most critical ones were selected for each of the model inputs. Each of the 5 series were used in the proposed, obtaining a reliability of $100 \%$ in the FCZ, as observed in Figure 7, given that the volume in the FCZ remained below the maximum allowed limit $\left(20 \mathrm{Mm}^{3}\right)$ for each of the selected series.

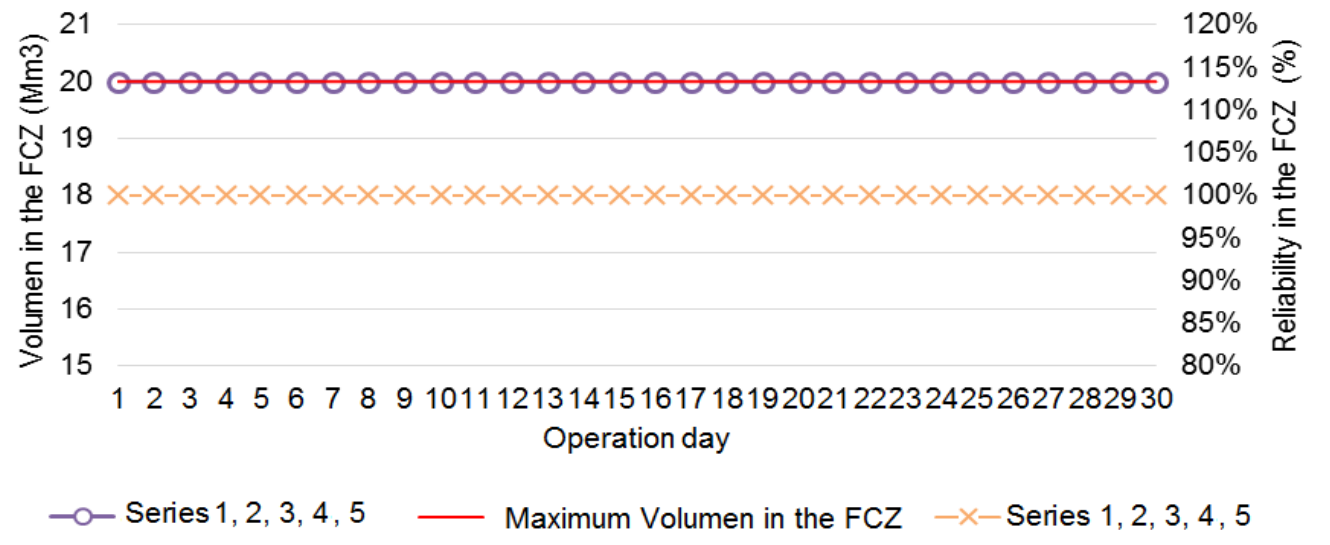

Figure 7. Maximum volume and reliability in the FCZ

A $100 \%$ reliability is achieved due to the control carried out over the generation discharges from Reservoir 2, as observed in Figure 8, while the generation through Reservoir 1, remained stable. This occurs because Reservoir 1 has a greater discharge capacity through generation, contributing to a greater extent to the fulfillment of the objective function.

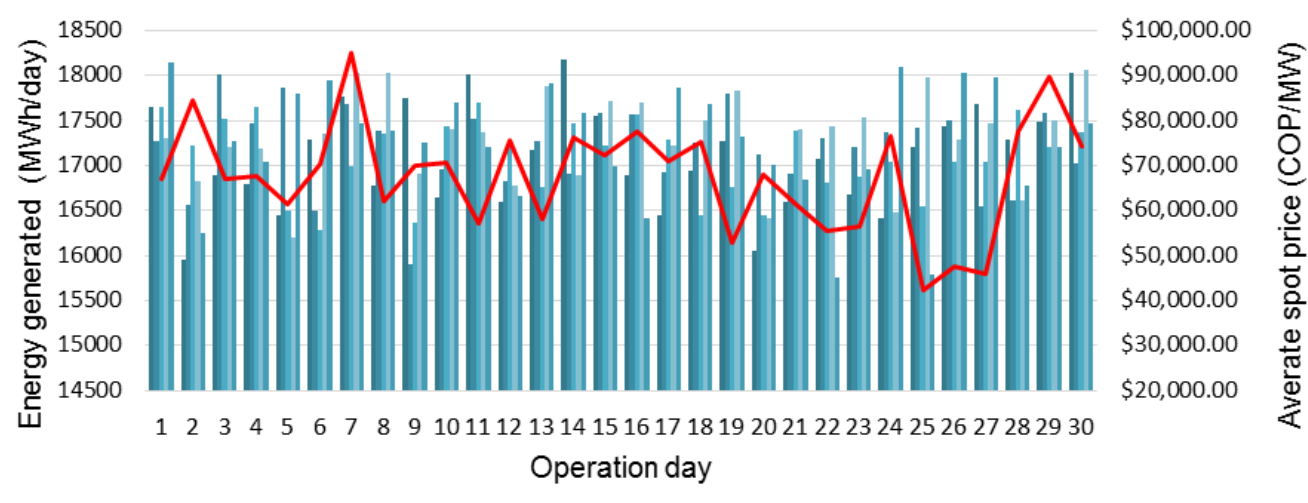

Figure 8. Energy generated by Reservoir 2 vs average spot price 


\section{CONCLUSIONS}

A food control model that incorporates stochastic elements was proposed in this paper. The stochastic model allows finding operating scenarios, under different hydrological conditions, based on historical information of water flows of the reservoirs under study. The data provided by the stochastic series generator are processed through a deterministic optimization model that takes into account the maximization of profits from energy sales as well as the constraints inherent to the operation of hydroelectric power plants, avoiding flooding in a given control area.

The proposed model considers the constraints inherent to generation plants that operate within an energy market, whose objective function is the maximization of profits under the guidelines of the country's regulatory framework. In the proposed model, the guidelines are given by the technical restrictions of the reservoirs and by the penalties for flood control in a given control zone.

The model and the proposed methodology can be incorporated by any generator agent or reservoir operator who is interested in validating the operating policies of hydroelectric power plants, to guarantee the required flows downstream of the reservoirs avoiding damage to the population.

\section{ACKNOWLEDGEMENTS}

The authors gratefully acknowledge the support from the Colombia Scientific Program within the framework of the call Ecosistema Cientifico (Contract No. FP44842- 218-2018). The authors also want to acknowledge Universidad de Antioquia for its support through the project Estrategia de Sostenibilidad.

\section{REFERENCES}

[1] H. Du y Z. Zhang, «Longyangxia and Liujiaxia Reservoirs Ecology Flood Compensation Benefits», IEEE 2012 World Autom. Congr., pp. 1-5, 2012.

[2] L. Guohua, W. Guoli, y X. Shufeng, «A Multi-reservoir Flood Operating System Based on Fuzzy Messages», 2009 Sixth Int. Conf. Fuzzy Syst. Knowl. Discov., pp. 22-28, 2009.

[3] X. Dong, J. Liu, Y. Li, H. Bo, y X. Deng, «Dynamic Application and Risk Analysis of Flood Control Water Level to the Three Gorges Reservoir by Utilizing MidTerm Inflow Forecasts», Power Energy Eng. Conf. (APPEEC), 2010 Asia-Pacific, pp. 1-5, 2010

[4] R. Beilfuss, «Modelling trade-offs between hydropower generation and environmental flow scenarios: a case study of the Lower Zambezi River Basin, Mozambique», Int. J. River Basin Manag., vol. 8, n. ${ }^{\circ}$ 34, pp. 331-347, 2010.

[5] D. Goutx, P. Mériaux, y R. Tourment, «Éléments de conception hydraulique des déversoirs des endiguements de protection contre les inondations», Ingénieries, vol. Spécial 20, pp. 169-178, 2005.
[6] L. Le Ngo, «Optimising reservoir operation. A case study of the Hoa Binh reservoir, Vietnam», Technical University of Denmark, 2006.

[7] T. Asfaw, K. Yusof, y A. Hashim, «Parameters Estimation and Rule Curve Development of Cascade Hydropower Reservoirs», Natl. Postgrad. Conf. (NPC), 2011, 2011.

[8] C. Fortier, A. Assani, M. Mesfioui, y A. Roy, «Comparison of The Interannual And Interdecadal Variability of Heavy Flood Characteristics Upstream And Downstream From Dams In Inversed Hydrologic Regime : Case Study Of Matawin River (Québec, Canada)», River Res. Appl., vol. 27, n. ${ }^{\circ}$ 10, pp. 12771289, 2011.

[9] J. W. Labadie, «Reservoir System Optimization Models», Water Resour. Updat., vol. 108, pp. 83-110, 1998.

[10] V. H. Bedoya y J. López, «Optimal Flood Control with a Hydroelectric Reservoir: a Colombian Case Study», Transm. Distrib. Conf. Expo. - Lat. Am. (PES T\&DLA), 2014 IEEE PES, 2014.

[11] S. F. Rodríguez-Corso, «Simulación dinámica de inundaciones asumiendo un estado crítico de máxima escorrentía, bajo cinco periodos de retorno, en la Quebrada la Viergen del Municipio de San José de Miranda-Santander», Rev. UIS Ingenierías vol. 17, no. 1, pp. 251-270, Ene. 2018.

[12] D. M. Rey, J. del C. Zambrano, «Estudio de la respuesa hidrológica en la cuenca urbana de montaña San LuisPalogrande. Rev. UIS Ingenierías vol. 17, no. 1, pp. 115-126, Ene. 2018.

[13] J. C. García, J. M. Ramírez, «Concepción de un simulador para el entrenamiento de operadores de centrales hidroelécricas y desarrollo del arranque de un generador», Rev. UIS Ingenierías vol. 16, no. 2, pp. 105-118, May. 2017.

[14] XM S.A. E.S.P., "Parámetros embalses del SIN," Parámetros técnicos del SIN, 2017. [online]. Availabe : http://www.xm.com.co. 